\title{
4
}

\section{Should the Concept of Hybridity Be Used Normatively as well as Descriptively?}

\author{
Miranda Forsyth
}

\section{Introduction}

This chapter explores the question of whether it is possible and useful to develop the concept of hybridity to answer questions about how legal/ regulatory systems ought to be, as well as describing how they currently work. This was a question that arose many times during the seminar series and workshop that this collection is based upon. It also reflects a tension that is often present in interdisciplinary contexts, particularly where anthropologists and lawyers are involved as their basic orientation (descriptive versus normative) is often so different. This chapter uses examples from Melanesia, primarily Papua New Guinea and Vanuatu, where I have conducted research in the area of law and development since 2002. 


\section{Approaches to law through a hybrid orientation}

There are a number of ways of theorising about law that are shared by many who adopt a hybrid approach to law. For the purposes of this chapter, it is helpful to sketch these out initially to clarify what is encompassed by such an approach, as many different concepts of hybridity exist in the literature. ${ }^{1}$ First, the concept of hybridity in the legal context involves a recognition that even in Western countries, and certainly and most obviously in indigenous communities and postcolonial national states, law also exists outside statutes and case law. ${ }^{2}$ Second, law is seen to be constructed by a wide range of institutions, and it is increasingly recognised that even individual legal subjects are 'law inventing' as well as 'law abiding. ${ }^{3}$ Third, there is acknowledgment that multiple legal orders co-exist in different overlapping spatial dimensions and typically shape one another through ongoing interaction. The relationship between legal orders-which are often neither entirely internally coherent nor externally differentiableis dynamic, mutually constitutive and mutually dependent. This process has been characterised by a variety of different terms-interlegality, ${ }^{4}$ interactional law, ${ }^{5}$ transnational legal orders, ${ }^{6}$ critical legal pluralism ${ }^{7}$ and hybridisation. ${ }^{8}$ The differences that exist between these different approaches is beyond the scope of this chapter. I will refer to a hybrid approach which should be taken to encompass the abovementioned insights, with the additional benefit of centring focus on the dynamic and porous nature of the relationship between legal orders.

These approaches to law unsettle the commonly held view of law as being created exclusively by legislatures and courts. However, departing from that well-trodden foundation raises a number of difficult questions: What is law? (And when does a social norm become law?) Who are the agents of law? (And whose voices and needs are privileged and whose are overlooked?)

1 Many people use the term 'hybrid' in a narrow legal sense to refer to hybrid institutions, such as village courts in Papua New Guinea. See, for example, Evans et al., 'The Hybrid Courts of Melanesia'. This is not the sense the term is used in this chapter. For more description see Brown, this volume.

2 Merry, 'Legal Pluralism'; Moore, 'Law and Social Change'.

3 Kleinhans and MacDonald, 'What Is Critical Legal Pluralism?'

4 Santos, 'Law: A Map of Misreading'; Santos, Towards a New Legal Common Sense.

5 van der Burg, The Dynamics of Law and Morality.

6 Halliday and Shaffer, Transnational Legal Orders.

7 Kleinhans and MacDonald, 'What Is Critical Legal Pluralism?'

8 Snyder, 'Colonialism and Legal Form'. 
What time periods are involved in bringing about legal change? What requirements for legitimacy exist in different legal systems? Where is law constructed? The concept of hybridity thus leads us onto uncertain ground, with more and more gaps and questions opening up the further one travels. Recognising that there are multiple different change agents, all operating in a semi-autonomous way, makes any deliberate program of positive social change through regulation highly challenging. This is the reason for seeking to develop analytical and conceptual methods to assist in both explaining the development of hybrid legal orders, and also in answering questions about if and how such developments can be steered in an emancipatory direction.

\section{Should hybridity be developed to answer the 'ought' as well as the 'is' questions?}

This brings us to the important issue of 'is' versus 'ought' or 'fact' versus 'norm' or, as many in the hybridity literature express it, questions of 'descriptive hybridity' versus 'instrumental hybridity'. 'The concept of hybridity has been widely accepted as being useful for answering the 'is' question; that is, how is law or regulation done in practice? It encourages legal reformers to move away from a positivistic and state-centric approach to law as being solely limited to legislation or case law, or, for that matter, customary law being conceived of as a coherent system of rules. ${ }^{10}$ For example, applying such a perspective to the issue of the regulation of intangible cultural heritage in Vanuatu, I have identified that rights are claimed and disputes are managed as a result of a variety of regulatory forces, including the need to maintain relationships, fear of the supernatural, avoidance of shaming and customary sanctions. ${ }^{11}$ A hybrid analytical framework provides a far wider view of regulatory forces than a myopic focus on written or unwritten norms, and assists in understanding the empirical reality of the various forces at play in the relevant social field.

9 Mac Ginty and Richmond, 'The Fallacy of Constructing Hybrid Political Orders'.

10 I term this customary positivism.

11 Forsyth and Farran, Weaving Intellectual Property Policy in Small Island Developing States. 
Much more contested is whether the concept of hybridity is also relevant for answering the 'ought' question; that is, how ought hybrid legal frameworks operate? This is often referred to as instrumental hybridity; I prefer the more value neutral term of normative hybridity. It should be noted in passing that in legal jurisprudence there is a history of debates over the relationship between empirical facts and normative questions of law (for example, the famous debate between Ehrlich and Kelsen), ${ }^{12}$ and so this tension has a long tradition.

A strong critique of instrumental hybridity has emerged quite recently in both the law and development and peacebuilding literature. ${ }^{13}$ This critique is in response to the embrace of hybrid approaches by international agencies and donors in the past decade, especially in the context of rule of law and statebuilding programs in conflict-affected and so-called fragile countries where the reach of the state is often limited and lacking in legitimacy. Moving away from a narrow state-centric framework has been seized upon as offering creative ways to overcome limitations of capacity on the part of state actors and to provide existing mechanisms that can be used to do the work that state agencies are not able to do. ${ }^{14}$ In some respects, this pragmatic use of hybridity resonates uncomfortably with colonial techniques of indirect rule, which involved mechanisms such as native courts, district assessors and the enrolling of local chiefs into the state justice system. ${ }^{15}$

Such instrumental approaches to hybridity have been criticised as involving 'jurisprudential technology', a 'set of templates and models through which the non-state legal orders are regulated and authorized'16 or 'hybrid programming' in the peacebuilding and development fields. ${ }^{17}$ These critiques point to the extent to which such approaches 'give license to intervention-giving credence to prescriptive approaches and legitimizing top-down technocratic solutions'. ${ }^{18}$ They are seen to facilitate the implementation of Western models in a local disguise, by creating institutions that are given a cloak of legitimacy as they purportedly comprise elements of both systems. There is also the concern that the

12 van Klink, 'Facts and Norms'.

13 See Hameiri and Jones, this volume.

14 Tamanaha et al., Legal Pluralism and Development.

15 Rodman, 'Men of Influence, Men of Rank'.

16 Porter, 'Some Implications on the Application of Legal Pluralism to Development Practice', 168.

17 Millar, 'Disaggregating Hybridity', 503.

18 Ibid., 511. 
'turn to the local' in international engagements-whether peacebuilding, statebuilding or development more broadly-facilitates or is in sympathy with external neoliberal agendas aimed at subcontracting state functions to non-state actors, thereby further hollowing out already weak states. ${ }^{19}$ A further difficulty identified by critics is that in the construction of institutional hybrids 'there is a reduction of complex social processes to simple rules or norms that mimic formal law' ${ }^{20}$ Reflections of this sort have led critical peacebuilding scholars such as Mac Ginty and Richmond to announce they are 'sceptical of the possibility of instrumentalizing hybridity' and that attempts to instrumentalise hybridity 'evades ethical questions relating to social and distributive justice'. ${ }^{21}$ Boege has similarly declared that 'hybrid political orders, hybrid security governance and hybrid peace cannot be instrumentally designed, crafted or constructed'. ${ }^{22}$

There is not the space here to discuss the substantive validity or otherwise of these critiques of previous uses of hybridity. ${ }^{23}$ The point I wish to make is that the way in which the concept has been used as an instrument of legal reform should not be a reflection on whether it should or could be used to answer normative questions about social justice (the 'ought' question). In other words, previous (for argument's sake, misguided) instances of using the concept in a normative way should not preclude future attempts to develop the conceptual insights of hybridity to better answer 'ought' questions concerning social justice.

There are a number of reasons to support this argument. The first is that those arguing against instrumentalised hybridity appear to base their argument on the grounds that those 'doing' hybridity are always outsiders or international actors, characterised as 'elites intent on modernization and marketization' ${ }^{24}$ and who get 'local actors to work in the service of strategic and liberal internationalist goals'. ${ }^{25}$ This characterisation ignores the broader view of agency that is one of the advances of hybridity; namely that regulatory change involves the conscious and unconscious interweaving of different aspects of different legal systems at many

19 Meagher, 'The Strength of Weak States?'.

20 Jayasuriya, 'Institutional Hybrids and the Rule of Law as a Regulatory Project', 152-153.

21 Mac Ginty and Richmond, 'The Fallacy of Constructing Hybrid Political Orders', 220.

22 Boege, this volume.

23 It is relevant in assessing such critiques that 'prescriptive hybridity' has been anchored in a larger critique of 'the liberal peace' that has characterised international peacebuilding over the past two decades.

24 Mac Ginty and Richmond, 'The Fallacy of Constructing Hybrid Political Orders', 230.

25 Ibid., 225. 
different levels and is driven by many different actors. As such, it involves both internal and external change agents, and often shifting coalitions of both, a point demonstrated by other chapters in this collection (for example, Dinnen and Allen). This is also something that has been thoroughly explored and documented by historical anthropology. ${ }^{26}$ One has only to look in Melanesia at the various initiatives at a customary level — such as the adoption of constitutions and by-laws by chiefly councils, the appointment of minute takers and even the creation of uniforms and letterhead for non-state justice processes - to see that hybridity is in no way limited to outside agents of change. ${ }^{27} \mathrm{It}$ is also incorrect to characterise external agents as uniformly driven by neoliberalising motivations and internal agents as not; it is abundantly clear that forces for and forces against capitalism and neoliberal development models exist along every part of the local to global continuum.

Second, in arguing against normative hybridity there is a failure to perceive a role for regulation, in the sense of 'the intentional activity of attempting to control, order or influence the behaviour of others ${ }^{28}$ or for governance, meaning 'steering the flow of events within a social system'. ${ }^{29}$ Richmond distinguishes between a negative hybrid peace, which 'may represent the outsourcing of power and norms from the international to the state or society', and a positive hybrid peace that 'implies that significant legitimacy and agency emerge from the local scale'. ${ }^{30}$ However, they imply that it will largely be a matter of happenstance, context and power dynamics that will lead to either one or the other. In other words, there is no room for conscious and informed regulatory design in steering or influencing movement towards particular hybrid formations (and any move in that direction is doomed to failure). I am puzzled by this; hybrid arrangements occur at least in part due to various degrees of conscience or deliberate reform by a range of actors. It may be that the intentions and actions of such change agents are thwarted at times by geopolitical or local power dynamics, but this should not rule out the possibility of directed positive change all together. It seems a worthwhile endeavour to enquire into, and theorise about, what sorts of processes of change and regulatory tools bring about what types of hybrid arrangements in which contexts.

26 Akin, Colonialism, Maasina Rule, and the Origins of Malaitan Kastom.

27 Forsyth, A Bird That Flies with Two Wings.

28 Black, 'Critical Reflections on Regulation', 25.

29 Gunningham, 'Confronting the Challenge of Energy Governance', 120.

30 Richmond, 'The Dilemmas of a Hybrid Peace', 51. 
Generating such insights will surely be of relevance for all those engaged in reform projects involving hybrid legal orders, and can help to avoid the shallow engagement with the concept that has been so problematic. In answer to the concerns of Mac Ginty and Richmond, I argue that it is precisely through such theorising that ethical questions relating to social and distributive justice associated with hybrid legal orders can be asked and debated.

A third argument is that the relationship between 'is' and 'ought' is itself highly interwoven, making separating the two problematic. ${ }^{31}$ This is supported by Braithwaite and Pettit who argue that we need to work harder to make our normative and explanatory theories work better together. They contend:

Any normative theory that works with a category that lacks explanatory resonance is likely to be utopian and it will serve our policymaking badly. Any explanatory theory that fails to connect with a normative concern is likely to be unguided and it will be incapable of serving policymaking at all. ${ }^{32}$

Developing normative hybridity further will therefore also enhance the value of hybridity as an explanatory concept.

\section{How could hybridity be developed to answer the 'ought' question?}

Having set out why it is worthwhile to consider how hybridity can be theorised on a normative level, I turn now to the question of how to do so. Once we start to think through the many questions involved it is not long before we run smack bang into issues of power and privilege. A useful theory of hybridity must therefore focus on these at its heart. Other and related issues are: Who decides which norms to pursue? Who has the authority and the power to bring about change in any legal system? If there are multiple legal systems, how can they all be taken into account if each system has only a partial perspective and conflicting objectives?

31 For instance, merely describing the existence of other normative systems-even to the extent of calling them 'law' — often creates a layer of additional legitimacy.

32 Braithwaite and Pettit, Not Just Deserts, 161. 
These are all large questions and the aim of this chapter is just to identify a few leads in beginning to develop a richer conceptual framework. I identify three starting points: focus on the values and objectives at stake, concentrate on the processes of change, and analyse the relationships between and within different legal orders.

\section{Focus on the values and objectives at stake}

Previous attempts to bring about social change using concepts that underpin hybridity have heavily focused on questions of structure, institutions and instruments (for example, written laws, police officers and customary compensation payments). This focus on institutional form $^{33}$ and other more easily identifiable aspects of the regulatory system often leads to the overlooking of values or principles that underlie different regulatory systems and reform agents. These values are often hidden through what Gramsci termed cultural hegemony ${ }^{34}$ and others assumptive normality, the process by which certain values come to be seen as 'natural' and hence taken for granted. This process has been identified by postcolonial scholars in relation to concepts such as human rights, the rule of law and development. ${ }^{35}$

Using hybridity to answer 'ought' questions requires explicit identification of the values, principles and objectives of any reform project and space created for debate over them. It thus brings to the forefront issues that often remain hidden in reform projects through generalised references to 'rule of law', 'capacity building' and 'peace'. What is required is a conscious reflexivity about the use of such terms, even those that are apparently widely accepted, such as 'justice'. Such a term can involve connotations associated with Western 'justice' systems, such as the importance of individual rights, consistency in judgements, a fair and open trial, impartial judges and the right to present a defence. However, in countries where I work, such as Vanuatu, these may not be the priorities of conflict management; rather, concepts such as the re-establishment of peace and harmony in the community and the restoration of relationships are often prioritised. The use of the term 'justice' may mask these fundamental

33 See Andrews, The Limits of Institutional Reform in Development.

34 Lears, 'The Concept of Cultural Hegemony'.

35 Escobar, Encountering Development; Pahuka, Decolonising International Law; Rajagopal, International Law from Below. 
differences in agenda, creating the assumption that all systems are reading from the same page when in reality there might be considerable divergence of opinion in what priorities should be pursued.

It is also important to highlight the tendency to underestimate the difficulty that everyone (aid and development practitioners, villagers, government officials) has in truly understanding new value systems or ontological realities (and in identifying them beneath the institutional form). This is often because values and principles are not explicitly articulated in many contexts-the focus is more on institutions and programs and processes (strengthening the justice system, for example). Many times concepts like 'justice' and 'rights' and 'victims' are understood very differently by different interest groups but this is often not perceived; a situation I and a colleague have elsewhere identified as being the 'false friends' problem. ${ }^{36}$ This borrows a linguistics concept that describes a situation of striking resemblance between two words in two different languages, leading speakers of each language to assume, incorrectly, that they understand the word's meaning in the other language. Even more problematically, the misunderstanding is hidden by the assumption of understanding.

For instance, in my work on sorcery-related violence in Melanesia, I have observed there is fundamental disagreement between international and local actors about what 'problem' requires regulation, and who the 'victims' of sorcery and witchcraft are. These disagreements are often not even realised as those with differing ideologies 'talk past' each other. For those who do not believe in the existence of sorcery, the 'problem' is the violence related to sorcery or witchcraft accusations, and the victims are those accused of being witches or sorcerers. For those who do believe, although there is often concern about sorcery accusation-related violence, the 'problem' is also (and for some primarily) the harm that sorcerers and witches do to their communities, killing and harming innocent people. From this perspective, the victims are those people who have been killed or hurt through sorcery or witchcraft. This spiritual/rational ontological divide is also observed in Boege's chapter in this volume, where he notes that spiritual rehabilitation was critical to the Bougainvilleans but only dimly understood by the international peacekeepers.

36 Forsyth and Haggart, 'The False Friends Problem for Foreign Norm Transplantation in Developing Countries'. 
In many ways, this is why issues such as sorcery, treatment of youth and gender-based violence are so important: they raise in stark relief these differences in value systems that otherwise remain covered over. So while such issues may seem to be particularly difficult for hybrid legal orders, they may in reality be the relatively low-hanging fruit-far more work needs to be done in other contexts in unearthing the different value systems because they are more deeply hidden.

It must be stressed that a focus on values and objectives should not imply that these are fixed, static or uncontested. The insights of hybridity apply equally here: values are in a constant process of adaptation/ mutual permeation and change and often involve power contestations. The suggestion here is simply to make these visible in order to facilitate more informed debate and include more voices, particularly those which are silenced by assumptions about the universality of values. A normative approach to hybridity must accept there will be disagreement about which norms to pursue and who gets to decide, but this will perhaps be easier to negotiate if there is generalised understanding about what is at stake.

\section{Focus on the processes of change}

Local-level hybrid arrangements are often seen as being more legitimate, authentic and positive than those 'designed' or constructed by the state or international actors. It is useful to unpack the reasons for this to understand if it is just because they are locally driven, or whether there are other explanatory processual factors behind this. Such factors may include the time span of the change (incremental or sudden), the underlying values in new regulatory arrangements, and whether existing power dynamics are reinforced and unchallenged. Understanding in detail which processes of change have which effects and why will give clearer insights into how better outcomes can be achieved through reform activities in hybrid legal contexts. It should also avoid lip service being paid to notions of 'consultation', 'local ownership' and 'bottom-up change'.

A much-needed dimension of research in this field is therefore the systematic identification of hybridising processes that enable positive/ liberal social change (acknowledging that what is 'positive' will always be relative and contingent). This will also involve identifying the agents of change, the values, implicit and explicit, being promoted and the extent to which all parties are in agreement over them, as well as how disagreements are managed. It is useful here to include processes that have led to 
successful hybridisation through conscious reform endeavours, and also hybridisations that have been less obviously directed. The question of who or what possesses intentionality and its role and limits in processes of change is highly relevant. ${ }^{37}$ Change impacts upon and is directed by structural factors, cultural prejudice and political, economic and ideological hegemony, and the extent to which these interplay with subjective intention requires further investigation.

My own research suggests positive reform in hybrid legal contexts is facilitated by the creation of spaces or forums that allow for active and well-informed debates about the objectives of particular reform projects, and the values and principles that underlie the desire to change. This notion comes from a number of different directions, including both the advocates of interculturality within the decolonial movement and from Habermas's concept of communicative action..$^{38}$ Quijano argues that in order to clear the path for 'new intercultural communication' there must be 'epistemological decolonization'. ${ }^{39}$ In other words, he suggests there can only be true communication between those from different cultures, and hence possessed of different ontologies or world views, if each party to the dialogue recognises the partiality of their perspective. Applying this notion to a legal context as an illustration, Tobin describes intercultural legal pluralism as 'a world of legal interfaces that cannot be imposed but must be negotiated, tested and modulated in response to the realities of differing worldviews, value systems and legal visions. ${ }^{40}$ Drawing these insights together means that such forums need to be places where difference is embraced; there is a willingness or incentive to learn; different value systems and ontological frameworks are explicitly articulated; each party to the dialogue recognises the partiality of their perspective; and there is an understanding that behind all regulatory systems are distinct logics, rationalities, customs and knowledge that must be taken into account. This is illustrated in some community development practices such as 'community conversations' around HIV in Melanesia. ${ }^{41}$

37 Latour's insights that it is not just people who have agency are highly relevant here. See Latour, Reassembling the Social.

38 Habermas, Theory of Communicative Action.

39 Quijano, 'Coloniality and Modernity/Rationality', 177.

40 Tobin, 'Bridging the Nagoya Compliance Gap', 161.

41 Reid, 'Re-thinking Human Rights and the HIV Epidemic'. See also Berman, 'Jurisgenerative Constitutionalism'. 
Those making conscious reforms in hybrid spaces need to find ways to create such spaces. This is in fact a space that academics can help to create through the holding of conferences, particularly in the countries where the issues involved are occurring, and including both scholarly and non-scholarly participants. One example of this I have been involved in was the holding of a series of conferences on the issue of sorcery accusation-related violence in Papua New Guinea. These have led to the creation of a coalition of local and international change agents and the development and passage of a new national policy to address this violence. ${ }^{42}$ The conferences also allowed for the working through of many of the difficult ontological issues associated with this area, such as how to address the violence while not denying people the right to their customary beliefs and practices.

The convening of conferences in a way that successfully creates such spaces is vastly more likely to be successful if international and local scholars, researchers and activists are able to plan, convene and publish together. It also requires proceedings of conferences to be made available and accessible (i.e. in plain English or where relevant translated) to those who will have practical need of them. This may involve creative approaches, such as publishing short summaries online, producing podcasts, holding information sessions or radio sessions, or other means. These are all real challenges for scholars in Western educational institutions where the political economy creates disincentives for these types of engagements, for example, pressures to publish single-authored papers in prestigious academic journals.

A concomitant part of the creation of such spaces is a recognition that no single approach works in every situation and there is intrinsic value in the mere fact that there are different ways of doing things. For example, a commitment to human rights principles may work wonderfully in relation to requiring everyone to be accorded a trial before conviction. However, it may end up being liberty depriving in dealing with genderbased violence in contexts where state agencies are themselves abusers of human rights. Other approaches may better ensure safety. There is also a need for recognition that notions such as human rights and rule of law are not a fixed-package option-people often do 'pick and mix' to use Helene Kyed's lovely term, ${ }^{43}$ in ways that to an outsider may be

42 Forsyth and Haggart, 'The False Friends Problem'.

43 At the workshop. 
unexpected, but seem to work in practice. For example, my research into dealing with sorcery-related violence in Melanesia indicates that one of the most effective ways for local leaders to deflect violence is to stress the absence of proof, a concept imported in this form from the state justice system.

\section{Focus on relationships between and within different legal orders}

Finally, there is a need to pay attention to the nature of linkages or relationships, formal and informal, between different legal systems or regulatory nodes within hybrid legal arrangements. ${ }^{44}$ As Baker has observed, relational ties within a network are crucial to determining the 'strength, cohesion, collaborative intensity and sustainability ${ }^{35}$ of the network as a whole. Such a statement is equally applicable to hybrid legal contexts which can be seen as a variety of network.

Focusing on relationships can involve looking at them both within legal orders and between legal orders through a range of different sections (in the sense of slicing up a specimen to look at under a microscope). This can be looking at all legal orders involved in a particular problem (such as domestic violence or intellectual property regulation) or all the legal orders involved in a particular geographical location. It can also be sliced temporally, to look at a particular moment in time or to take a long historical perspective.

Further, rather than stopping at the analytical stage, I am interested in the potential that exists to consciously change the nature of these relationships. A number of different regulatory theories have been developed in a Western context that may have relevance to such a project. Regulatory theories are not prescriptive about regulatory design; rather, they articulate insights about general principles that can be used in certain contexts to create regulatory systems that are more legitimate and less dominated by those with power. Below, I set out two that have the potential to be developed further in this context.

44 This is a topic on which much legal pluralism literature exists. See, for example, the discussion in Berman, 'Jurisgenerative Constitutionalism', where he identifies dialectical legal interactions, margins of appreciation, subsidiary schemes, hybrid participation arrangements and jurisdictional redundancies.

45 Baker, 'Linking State and Non-state Security and Justice', 600. 
The first is responsive regulation, which is based on the empirical insight that ensuring compliance with a particular regulatory objective can sometimes be achieved with persuasion and education, and sometimes requires heavier sanctions. It is based on the idea of a regulatory pyramid that gives the cheaper and more respectful options (education, mediation, community conversations) a chance to work first, while keeping the more costly punitive attempts at control in reserve for those cases where persuasion fails. ${ }^{46}$ Responsive regulation was designed in developed economies, but has recently started to be expanded to the developing world. In such a context it can be usefully supplemented with a networked or nodal governance dimension. ${ }^{47}$ This means that rather than dealing with a particular regulatory problem by itself, the state enrols a range of other actors (community organisations, civil society, church organisations, other states, United Nations organisations, academic institutions) in its efforts to ensure compliance. This is a potentially valuable approach in developing countries where the state does not have sufficient justice resources and there is a range of non-state actors offering assistance, especially in relation to issues such as gender-based violence. The challenge is for all the initiatives at work to be developed into an effective regulatory pyramid, so they meaningfully support each other. Responsive regulation coupled with network governance has clear relevance for situations of hybrid legal arrangements. It would need to be adapted further, however, to integrate the dynamic and coproducing nature of hybrid legal orders and also to deal more explicitly with questions of power, differences in ontology and the avoidance of domination.

The second regulatory theory of potential relevance is a conflict web concept I have developed ${ }^{48}$ that draws on network theory, ${ }^{49}$ nodal governance ${ }^{50}$ and regulatory space metaphors. ${ }^{51}$ The key features are as follows: first, it focuses on identifying, strengthening and, where necessary, building mutually supporting linkages between actors and institutions actively involved in conflict management (or indeed any other field). This avoids the adoption of a hierarchical, state-centralist approach to reform and frees up reform initiatives to consider how, for example, state

46 Braithwaite, 'Responsive Regulation and Developing Economies', 887.

47 Drahos, 'Intellectual Property and Pharmaceutical Markets'.

48 Forsyth, 'Spinning a Conflict Management Web in Vanuatu'.

49 Wellman, 'Network Analysis: Some Basic Principles'.

50 Shearing and Wood, 'Nodal Governance, Democracy, and the New "Denizens"'.

51 Scott, 'Analysing Regulatory Space'. 
institutions can be positively influenced by and kept in check by nonstate actors and institutions. ${ }^{52}$ It also helps to ensure that agents of reform (be they state governments or international donors) are not duplicating the efforts (or worse, inadvertently undermining the efforts) of another reform project.

Second, this framework emphasises the sharing of information about what reform initiatives work and why between various state and nonstate actors in the field and also donors, non-government organisations and academics. This will foster homegrown adaptation and innovation to replace the current tendency to look immediately outside for ideas and models. In turn, this is likely to increase the legitimacy of conflictmanagement institutions and actors, which has been identified as an important issue in statebuilding and reducing conflict and violence. ${ }^{53}$ Action learning and reflection are thus central to the framework, meaning that those involved in reform should regularly assess the benefits of their projects to inform themselves, and others in the web, about how to better implement reforms. ${ }^{54}$

\section{Conclusion}

This chapter has argued that the concept of hybridity can and should be developed to answer questions of how hybrid legal orders ought to be, a dimension to the concept termed here normative hybridity. It suggests three initial ways forward in developing these elements of the concept; namely a focus on the values at stake, a focus on the processes of change, and a focus on the relationships between and within different legal orders. It also suggests two regulatory theories that may prove useful for further developing this concept, noting that these ideas are as yet undeveloped and there is a need for further empirical testing and development. Developing the concept of hybridity in this way can facilitate change agents in helping to steer hybrid legal orders in positive and emancipatory directions.

\footnotetext{
52 Ibid., 337.

53 World Bank, World Development Report 2011, 84.

54 A collaboration-strengthening pyramid such as suggested by Braithwaite may also assist in this evaluation and strengthening process. See Braithwaite, Restorative Justice and Responsive Regulation, $115-127$.
} 
This text is taken from Hybridity on the Ground in Peacebuilding and Development: Critical Conversations, edited by Joanne Wallis, Lia Kent, Miranda Forsyth, Sinclair Dinnen and Srinjoy Bose, published 2018 by ANU Press, The Australian National University, Canberra, Australia.

doi.org/10.22459/HGPD.03.2018.04 